\title{
Bureaucracy and Challenges in Digital Era: A New Concept of Information Technology Integration in the Archipelagic Country
}

\author{
Saiful Deni ${ }^{1, ~ *}$, Thamrin Husain ${ }^{1}$, Aji Deni ${ }^{2}$ \\ ${ }^{1}$ Department of Administration Science, Universitas Muhammadiyah Maluku Utara, Ternate, Indonesia \\ ${ }^{2}$ Department of Political Science. Universitas Muhammadiyah Maluku Utara, Ternate, Indonesia
}

Email address:

saifuldeni@ummu.ac.id(S. Deni)

${ }^{*}$ Corresponding author

\section{To cite this article:}

Saiful Deni, Thamrin Husain, Aji Deni. Bureaucracy and Challenges in Digital Era: A New Concept of Information Technology Integration in the Archipelagic Country. Journal of Public Policy and Administration. Vol. 4, No. 4, 2020, pp. 71-77. doi: 10.11648/j.jppa.20200404.12

Received: October 21, 2020; Accepted: November 3, 2020; Published: November 16, 2020

\begin{abstract}
This study discusses a new concept on the integration of information technology government management in the archipelagic country. Data were obtained from several websites and social media applications on government matters in North Maluku and surrounding areas. Qualitative analysis is performed on all data collected using the Nvivo 12 application. The study results show that the concept of digital governance augments services of age with the availability and advancement of technology, a strategic and practical public sector. Formulating roadmaps of community digital information systems and egovernment include practitioners, online fiscal transparency, performance reporting, improving citizen participation, privacy issues in e-governance, elections via the internet, and E-government network at the local level governance level. EGovernment is based on technology policy and digitization policy bureaucracy that is accessible to the community. EGovernment regulations include open governance, privacy protection, social media, democracy, organization innovation, managerial efficiency, public service delivery, and citizen involvement. This new concept significantly addresses various government management problems towards the excellent and clean government, especially in an archipelagic country like North Maluku Province, Indonesia. This study requires ongoing studies on the evaluation and performance of government websites in encouraging openness, data availability, dynamic interactions, and accuracy of various data, users, and digital service systems.
\end{abstract}

Keywords: Public Services, People Welfare, Clean Government, Bureaucracy Performance, E-government

\section{Introduction}

Globalization and modernization as a way to facilitate various bureaucratic activities, the 21 st century is characterized by a shifting pattern of state and community relationships. Bureaucratic and corporate powers represent the state, users of technology and information, data storage, digital archives, and power sources controlled through software. Of course, the readiness of human resources, digital networks, service patterns, and borderless interactions is much faster and useful for more uncomplicated relationship and transaction mobility. The use of information technology (Informative technology) is actually to facilitate the complexity of bureaucratic dominance. The use of IT systems in bureaucracy to power the bureaucracy function is cheaper, faster, transparent, and integral. IT bureaucracy as a keyword in overcoming partition, boundary, geographical conditions. As an archipelagic country, the geological term, which is dominated by thousands of islands, influences the cost of service, time, process, results, and integrated system. Some strategic components such as (1) the integration of value systems between technologies, (2) multi-functional bureaucratic structures, (2) maps and patterns of geographical difficulty levels, (4) Technological operations financing capability and (5) the availability of professional human resources as a mutually influential link.

Based on these conditions, a new concept of implementing information and technology systems in the archipelagic 
country significantly to study. The study aims to discuss the new integration concept of bureaucratic information and technology systems in the archipelago. The results of this study will assist the government in improving the quality of public services.

\section{Literature Review}

The phenomena of electronic-based governance, especially the public sector services using the internet and digital device information services, network democracy, video imaging, and graphical interfaces, have allowed governments to develop websites that contain a variety of online materials [1]. As more people take advantage of these features, the digital government replaces traditional ways of access based on personal visits, phone calls, and mail delivery [1]. Along with the advancement of technology, public sector services through the government are strategic and practical [2]. In some cases, a definite correlation pattern between digital governments and a more productive employee service model is found [3].

The relationship between government and digital information systems has two links to a close citizen-centric perspective of the dual-component e-government and egovernance. E-government refers to online public reporting practices by Governments to citizens and delivery of services over the internet. E-Governance is an initiative for citizens to participate and to give their opinions on the government website [4]. E-Government must be a more oriented practitioner, contributing to various models and implementations online fiscal transparency, performance reporting, improving citizen participation, privacy issues in E-governance, elections, and e-Government network at the local level of government [4].

Indeed, the Digital governance Project has an impact. Analyzing the digital government requires the contribution of digital technology, measuring digitization, and answering questions about how Governments supervise legal obligations on information technology regulations. The state has formulated an excellent digital governance strategy, but it does not effectively offer and implement policies and programs that fit the local needs. The country ideally formulates specific plans that deliver results and can help policymakers, knowledge specialists, and public sector researchers to develop best practices for future national strategies [1]. E-Government is based on policies, processes, and technology. The policy relates to the origin and revitalization of government policies, e-government practices, and technological implementation [5].

The requirements of digital bureaucracy must be initiated by governance and effective coordination in an environment involving distributed knowledge and power. E-Government is a configuration between it and public sector governance designed to address spatial (geography and venue), Digital (communication and time), as well as cognitive (knowledge and education) [6]. The study of digital bureaucracy serves to help service and interaction through the world of Internet machines because it is more comfortable. IT is a cross-border corporation tied by an international network of technologies penetrating all users and direct government mobility to egovernment [7, 8]. The Digital government is a form of reconfiguring public administration, policy, and power. These Three things are manifested in digital information as a transformation model of public service [9]. Countries are obliged to innovate and institutional entrepreneurial movements in the form of the digital economy by considering its impact and influence (Tumbas, Berente, \& vom Brocke, 2018). It will herd to direction e-business model integration in the economic government field As Solution In Orientation Based Community [10].

The digital government requires two aspects, namely technology and public sector progress [1], how the digitization of services is more relevant and useful for frontline service providers and targeted citizens. The Digital government must have an appointment with system and service innovations between users (both service providers and end-user services). Change is the system development and users of how designers and users interact and open up possibilities for innovation to happen through the use of more effective technology by users [11].

E-Government also prioritizes open governance, privacy protection, social media, democracy, innovation in an array of e-Government projects between organizations, and open data systems to improve managerial efficiency, public service delivery, and citizen involvement [12]. Some recent research and recommend solutions to improve the implementation of E-Government will help achieve a more transparent, participatory, and democratic community. E-Government is characterized by open access to researchers, policymakers, public managers, organizations, and technical geeks. Digital Media is expected to change the way people understand and study the organization by Conceptualizing Digital organizing as an intense affective intensification. Organizing here must be integrated with a collection of technology media and human actors loaded, moved, and contested. The capabilities of digital media expand the relational organizing power of affective forces to be able to deal with economic change [13]. The Digital system in any organization taking the lead role can articulate and develop "digital" action logic, enforcing digital logic for innovation with digital technology. The Digital government can realize political relations, democracy, and participation of various components [14].

Trust and accountability in the digital age include some key points, i.e., interactive computer services available for education availability, control over the information they receive, political diversity, and culture; and interactive media a variety of political, educational, cultural, and entertainment services [15]. The availability of data on the various dynamics of governance can be used to supply several concepts about the similarity developed in the digital bureaucracy [16]. The governments, while taking policies, ideally promote the development of interactive computer services, encouraging the development of technologies that maximize user control over what information is received by individuals, families, and schools that use. The utilization of 
blocking technology and filtering it empowers parents to restrict children's access to objectionable or inappropriate online material; Preventing and punishing the trafficking of profanity, stalking, and harassment, obscene, profane, gross, excessive, violent, harassing, or objectionable [17]. The Digital revolution in Indonesia has changed the lifestyle and use of digital technology, work, culture, and identity in Indonesia. Other considerations relate to government agencies' behavior in political neutrality in the digital era with various challenges and administrative ethics [18, 19]. The example of the e-government framework, as presented in Figure 1.

\section{e-Government Framework}

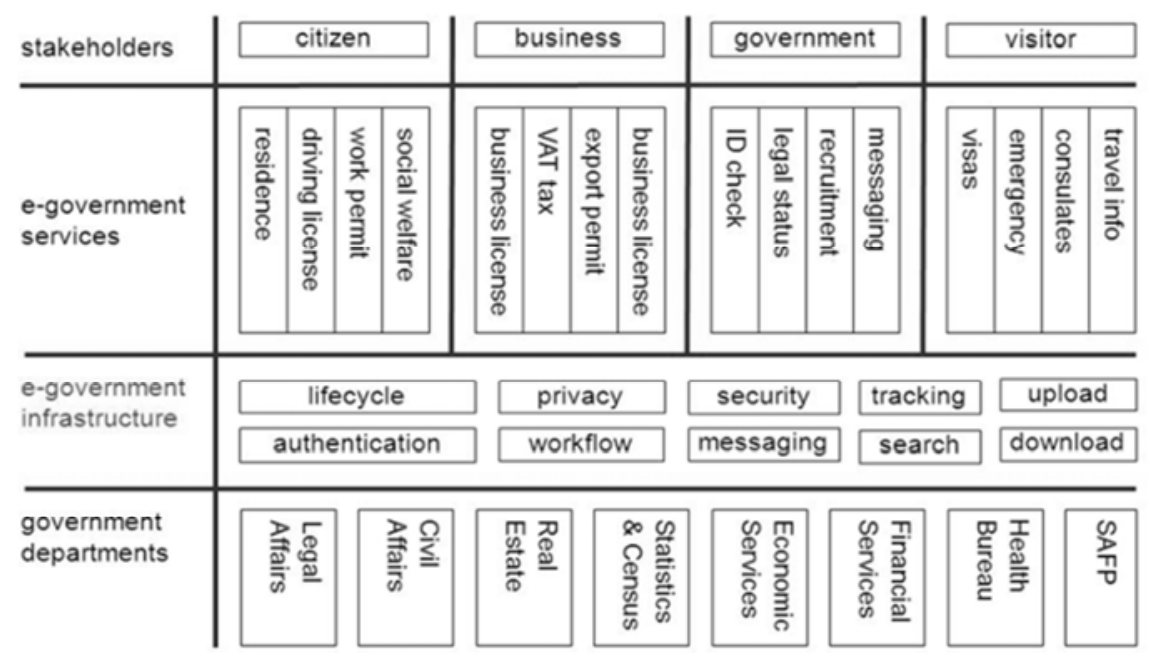

Source: Example of a relationship and Flow E-Government, https://slideplayer.com/slide/5207261/.

Figure 1. A Relationship and Flow E-Government.

Table 1. Top 10 Countries with the Highest Number of Internet Users in March 31, 2019.

\begin{tabular}{lllll}
\hline Country Region & Population 2019 Est. & Population 2020 Est. & $\begin{array}{l}\text { Internet Users March } \\
\mathbf{3 1 , 2 0 1 9}\end{array}$ & $\begin{array}{l}\text { Internet Users Dec } \\
\mathbf{3 1 , 2 0 1 9}\end{array}$ \\
\hline China & $1,420,062,022$ & $1,283,198,970$ & $829,000,000$ & $22,500,000$ \\
India & $1,368,737,513$ & $1,053,050,912$ & $560,000,000$ & $5,000,000$ \\
United States & 329,093110 & $281,982,778-2020$ & 3.584 \\
Brazil & $212,392,717$ & $176,287,587$ & $292,892,868$ & $95,354,000$ \\
Indonesia & $269,536,482$ & $211,540,429$ & $149,057,635$ & $5,000,000$ \\
Japan & $126,854,745$ & $127,533,934$ & $143,260,000$ & $2,000,000$ \\
Nigeria & $200,962,417$ & $122,352,009$ & $118,626,672$ & $47,080,000$ \\
Russia & $143,964,709$ & $146,396,514$ & $111,632,516$ & 200 \\
Bangladesh & $168,065,920$ & $131,581,243$ & $109,552,842$ & 2.800 \\
Mexico & $132,328,035$ & $101,719,673$ & $92,061,000$ & $3,100,000$ \\
\end{tabular}

\section{Discussions}

\subsection{The Readiness of Digital Infrastructure in Indonesia}

Activities include Twitter, Instagram, WhatsApp, Line, Path, and Telegram. Based on Indonesian infographics, of course, the classification of service quality differs between regions: Indonesian west, central Indonesia, and East Indonesia. Of course, bureaucratic digitization services with the availability of digital technology infrastructure. As information material, the availability of digital infrastructure in the form of fiber optic cable network has been started since 1998 (Nusantara 21), the year 2005 (National fiber Optic ring (CSO-N) of West Indonesia
North Sumatra-Papua West Papua along 25,000 km highspeed access 300 Gbps to 1,000 Gbps; and Palapa Ring able to reach 34 provinces, 440 City / District along 35,280 kilometers Kabal bring the sea and 21,807 kilometers of cable on land. The top 20 countries with the highest internet users in 2019, as seen in Table 1.

The potential of Internet users in Indonesia is the 5th largest in the world. The Top 20 Countries with the highest number of Internet users, March 2019, puts the highest order in China, India, USA, Brazil, Indonesia, Japan, Nigeria, Russia, Bangladesh, and Mexico. Annual Report of Ombudsman year 2018 shows that the highest report through the line comes directly at the office $59.39 \%$, letter $22.76 \%$, call $8.23 \%$, Email $3.86 \%$, incisory investigation $3.75 \%$, 
Media $1.74 \%$, and Website only $0.27 \%$. This Data shows that public awareness in utilizing government agency Websites is still very limited in number.

\subsection{Digital Interaction Analysis in Official Twitter Governance and Other Institutions}

This analysis uses NVivo 12 Plus Software by looking at the digital interaction patterns against service users, Hashtag/Tagar, through disseminated messages, duration, and charts within a given period. Not all government agencies have official Twitter that is professionally managed. It is mainly in the level of local governance; news through Twitter is still less continuity. Even some Twitter is already vacuum because without known the reason. The result of the analysis, as in Figure 2.

This point attempts to analyze some Twitter owned by government agencies. For example, in analyzing Twitter, the
North Maluku government, its activities can be known through various news and information dissemination on multiple fields and other agencies' networks. The percentage of results in Chart/graph shows the level of public interaction, the government of other institutions through communication function in the provincial government of North Maluku. The chart below shows the interaction patterns based on interactions between provinces across the region, online media involvement through various sectors of development, culture, law, economics, tourism, security, entertainment, business, events, news, places (Ambon City, Jakarta, Ternate City, Saumlaki). The number of references by Hashtag, as explains in Figure 3 shows the percentage of Twitter news access to North Maluku from January 2016 to December 2019. The interaction of the high-level incentive of incentives occurred in April-June 2017, January-March 2018, and July-September 2018.

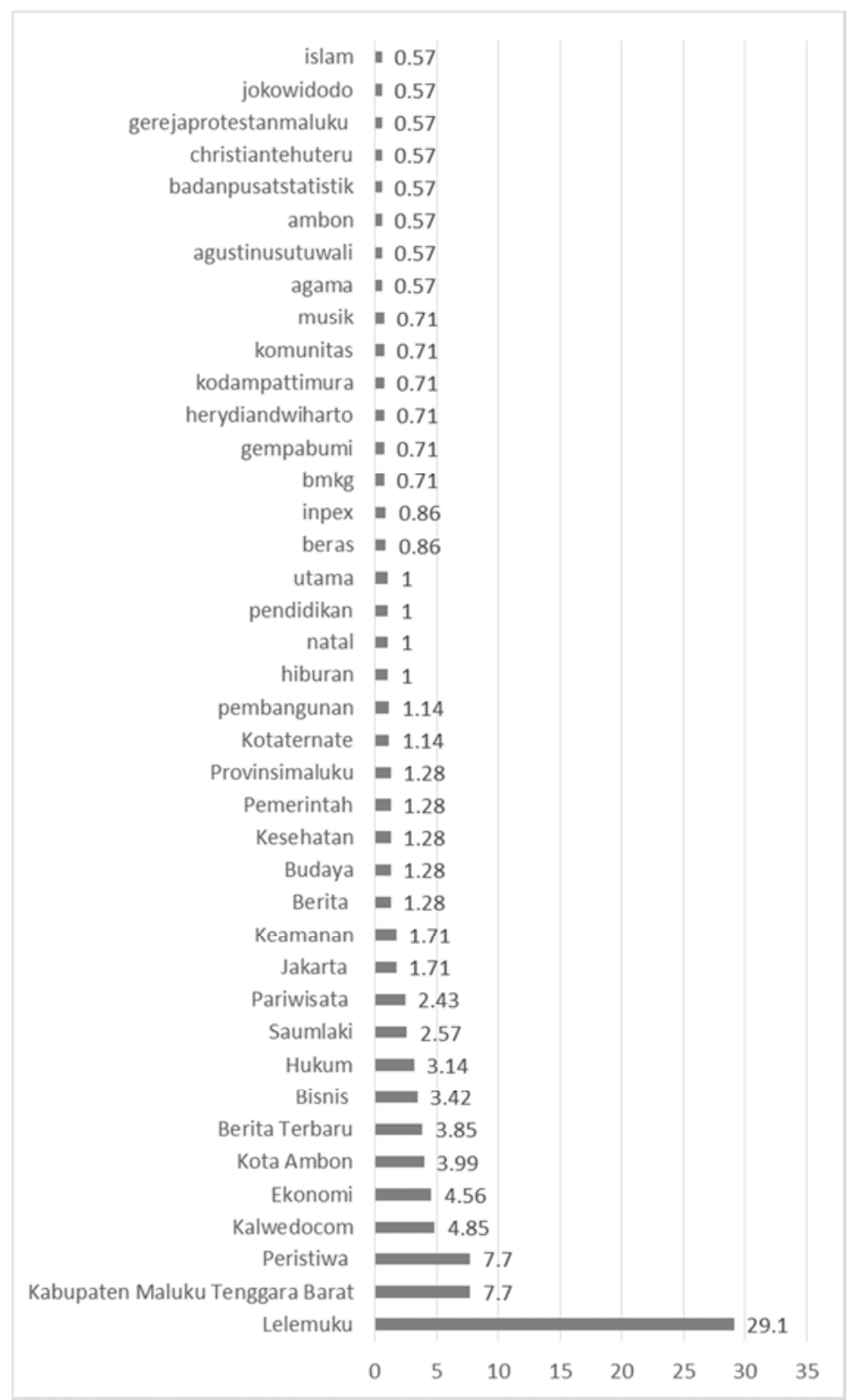

Figure 2. Analysis result of NVivo 12 Plus application. 


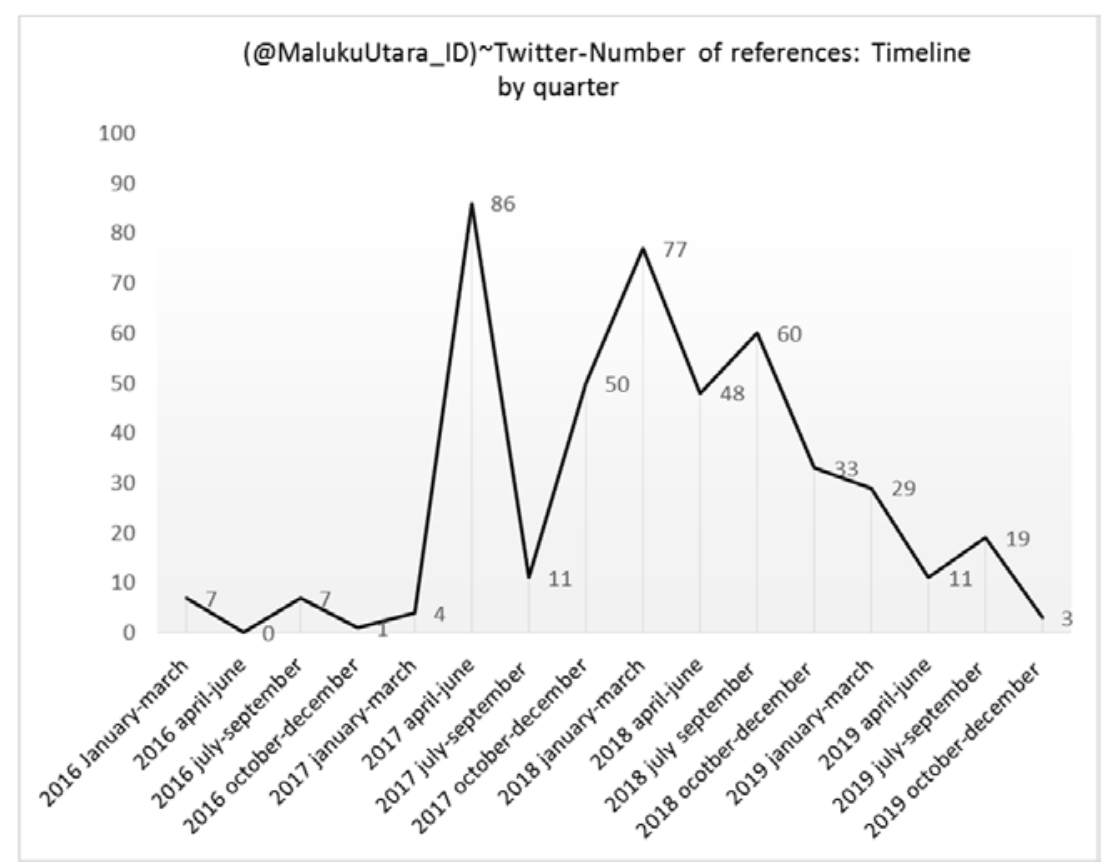

Figure 3. The percentage of Twitter news access to North Maluku in January 2016 to December 2019 period.

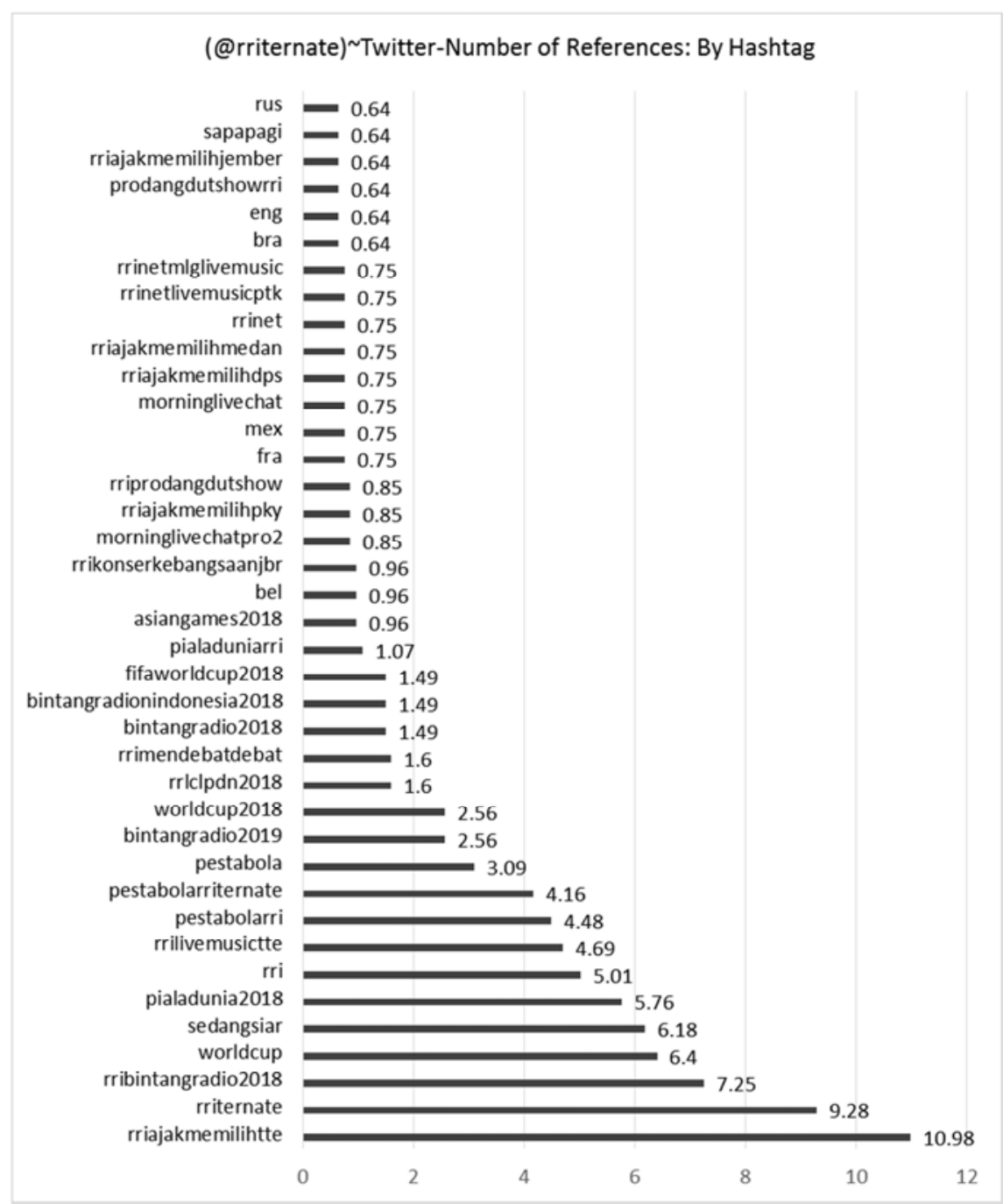

Figure 4. The presentation of Hashtag/Tagar charts based on the news type. 


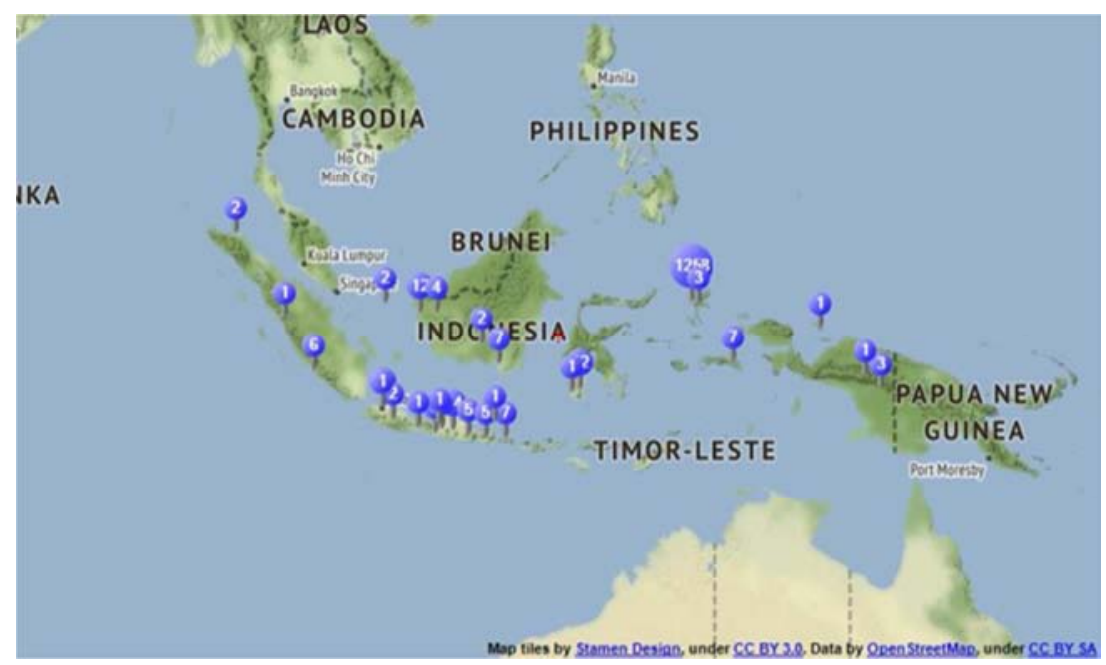

Figure 5. Map of RRI Ternate Twitter Hashtag Distribution.

In addition to the affordability of interactions in distribution news based on Twitter folder Analysis, RRI Ternate can be obtained some nominal data. The higher level of digital communication occurs in the North Maluku region, followed by Java, Kalimantan, Sumatra, Papua, and Maluku, as seen in Figure 5.

\section{Conclusion}

E-Government is based on technology policy and digitization policy bureaucracy that is accessible to the community. Digital bureaucracy must be initiated by governance to address spatial (geography and place), digital (communication and time), as well as cognitive (knowledge and education). IT and its cross-country corporations as a tool in reconfiguring public administration, policies, and powers cover institutional, digital, and economic entrepreneurship Oriented Based Community. E-Government regulations include open governance, privacy protection, social media, democracy, innovation in the organization, managerial efficiency, public service delivery, and citizen involvement.

As an archipelago province, the provision of digital governance infrastructure as an effective way to cope with communication patterns and costly interaction costs. Of course, the rule of supporting facilities such as logistics, technology base infrastructure and IT is more useful archipelago-based and addressing more targeted public services. The results of the watch care, some government structures do not have and empower E-Government applications in North Maluku. Many government websites are not appropriately managed, and data has expired, low management, and power of professional human resources in managing government sites. It requires serious attention from leaders, heads, regions, DPRD, public service practitioners, and IT practitioners to collaborate on changes and advances in digital governance.

This study requires ongoing studies on the evaluation and performance of government websites in encouraging openness, data availability, dynamic interactions, and accuracy of various data, users, and digital service systems.

\section{References}

[1] M. Darrell West. (2005). Digital government: Technology and public sector performance. Princeton University Press.

[2] Al Ajeeli, A. T., \& Al-Bastaki, Y. A. L. (2010). Handbook of research on e-services in the public sector: E-government strategies and advancements. Handbook of Research on EServices in the Public Sector: E-Government Strategies and Advancements, 1-523. https://doi.org/10.4018/978-1-61520789-3.

[3] Fugini, Grazia, M., Maggiolini, P., \& Ramon Salvador Valles. (2014). E-government and employment services: a case study in effectiveness. Springer.

[4] Manoharan, A. (2014). E-government and websites: A public solutions handbook (A. Manoharan, ed.). Routledge.

[5] Gottschalk, P., \& Solli-sæther, H. (2008). Stages of egovernment interoperability. 5 (3), 310-320.

[6] Khosrowpour, M. (2005). Practicing E-government. IGI Global.

[7] Archer, N. (2008). Mobile e-health: Making the case. Medical Informatics: Concepts, Methodologies, Tools, and Applications, 1-4, 95-106. https://doi.org/10.4018/978-160566-050-9.ch009.

[8] Dunleavy, P., Margetts, H., Tinkler, J., \& Bastow, S. (2006). Digital era governance: IT corporations, the state, and egovernment. Oxford University Press.

[9] Whyte, J. (2019). How Digital Information Transforms Project Delivery Models. Project Management Journal, 50 (2), 177194. https://doi.org/10.1177/8756972818823304.

[10] Chhabra, S. (2009). Integrating E-Business Models for Government Solutions: Citizen-Centric Service Oriented Methodologies and Processes: Citizen-Centric Service Oriented Methodologies and Processes (S. Chhabra, ed.). IGI Global. 
[11] McLoughlin, I., \& Wilson, R. (2013). Digital government at work: a social informatics perspective. OUP Oxford.

[12] Muñoz, L. A., \& Bolívar, M. P. R. (2017). International EGovernment Development: Policy, Implementation and Best Practice (L. A. Muñoz \& M. P. R. Bolívar, eds.). Springer.

[13] Beverungen, A., Beyes, T., \& Conrad, L. (2019). The organizational powers of (digital) media. Organization, 26 (5), 621-635. https://doi.org/10.1177/1350508419867206.

[14] Reddick, C. G. (2020). Politics, Democracy and EGovernment: Participation and Service Delivery. Memory.

[15] O'Neill, O. (2020). Trust and accountability in a digital age. $\begin{array}{llll}\text { Philosophy, } & 95 & \text { (1), } & \text { 3-17. }\end{array}$ https://doi.org/10.1017/S0031819119000457.

[16] Whelan, A. (2019). "Ask for More Time": Big Data
Chronopolitics in the Australian Welfare Bureaucracy. Critical Sociology. https://doi.org/10.1177/0896920519866004.

[17] Jurriëns, E., \& Tapsell, R. (2017). Challenges and opportunities of the digital 'revolution' in Indonesia. Digital Indonesia: Connectivity and Divergence, 2020, 275-288. https://doi.org/10.1355/9789814786003-007.

[18] Tumbas, S., Berente, N., \& vom Brocke, J. (2018). Digital innovation and institutional entrepreneurship: Chief Digital Officer perspectives of their emerging role. Journal of Information Technology, 33 (3), 188-202. https://doi.org/10.1057/s41265-018-0055-0.

[19] Nugroho, R. A., Shaila Putri, D. P., Santoso, T. B., Utomo, D. R., \& Setyowati, K. (2019). Government Official Political Neutrality in Digital Era: Challenge for Administrative Ethics? Iapa Proceedings Conference, (1978), 406. https://doi.org/10.30589/proceedings.2019.244. 